\title{
Housing Tenure, Energy Consumption and the Split-Incentive Issue in Australia
}

\section{Authors}

\author{
Gavin Wood \\ School of Global Studies, Social Science and Planning, RMIT University \\ Rachel Ong
}

Centre for Research in Applied Economics, School of Economics and Finance

Curtin University

Clinton McMurray

Centre for Research in Applied Economics, School of Economics, and Finance

Curtin University

Contact: Clinton McMurray, School of Economics and Finance, Curtin Business School, Curtin University

Postal address: GPO Box U1987 Perth, Western Australia 6845, Australia

Telephone: + 61892663976

Email: c.mcmurray@curtin.edu.au

Acknowledgement: The research reported in this paper was funded by grant number 40560 from the Australian Housing and Urban Research Institute (AHURI). The authors would like to thank Michelle Gabriel, Phillipa Watson and Maryann Wulff for their comments on the paper's research. The authors would also like to thank Richard Seymour, who coded up the 2006 rules governing eligibility for energy rebates in Australia, which has enabled us to distinguish between households that are eligible and ineligible for these rebates. This paper uses unit record data from the Household, Income and Labour Dynamics in Australia (HILDA) Survey. The HILDA Project was initiated and is funded by the Australian Government Department of Families, Housing, Community Services and Indigenous Affairs (FaHCSIA) and is managed by the Melbourne Institute of Applied Economic and Social Research (MIAESR). We are grateful to two anonymous referees for helpful comments on an earlier version of this paper. The findings and views reported in this paper, however, are those of the authors and should not be attributed to either FaHCSIA or the MIAESR. 


\title{
Housing Tenure, Energy Consumption and the Split-Incentive Issue in Australia
}

\begin{abstract}
In recent years, there has been growing global recognition of the need to reduce carbon emissions in response to climate change concerns. It is generally acknowledged that the energy efficiency of existing homes can be improved, but there are significant barriers to its uptake. In particular, improving the energy efficiency of private rental housing presents unique policy challenges due to a split-incentive problem. This has prompted some governments to introduce programmes that encourage landlords to improve the energy efficiency of their properties. While landlords are responsible for the purchase of many energy-consuming household appliances, tenants are responsible for energy bills. Since the landlord does not reap the immediate benefits of investment in energyefficient equipment, the incentives motivating such investment are weaker than for home owners. This paper aims to quantify the magnitude of the split-incentive problem in the Australian private rental housing market by invoking a modelling approach where energy expenditure is estimated as a function of housing tenure, dwelling type, location, climate and other socio-demographic variables. We find no evidence in support of the split-incentive hypothesis in Australia. The paper concludes that differences in housing policy arrangements could be critical to the presence and importance of split incentives.
\end{abstract}

\section{Keywords:}

Housing tenure, energy consumption, split-incentives, principal-agent problem

\section{Introduction}

Global carbon dioxide emissions have risen by more than $20 \%$ over the last decade (International Energy Agency, 2007). This has led to growing recognition globally of the need to implement policies that aim to reduce carbon dioxide emissions and promote energy efficiency. The residential sector is a significant source of emissions. For example, in the United States, the residential sector produced 1,220 million metric tonnes of carbon dioxide in 2008, which amount to $21 \%$ of total carbon dioxide emissions by United States end-use sectors in that year (U.S. Energy Information Administration, 2009). ${ }^{\mathrm{i}}$ In Australia, the residential sector accounted for $16 \%$ of emissions in 2006 (Garnaut, 2008).

In both countries private rental housing accounts for around 20 to 30 per cent of the housing stock (see Andrews, Caldera Sánchez and Johansson, 2011, figure 5). But improving the energy efficiency of private rental housing presents important policy challenges due to a split incentive or principalagent problem. In general terms, a split incentive issue arises when an agent acts on behalf of a principal, managing resources that are 'owned' by the principal. But the interests of the agent are not aligned with those of the principal. Such agency problems may be present in many types of economic activity, and with respect to other types of property (e.g. commercial) where ownership and use are divorced. In the present context the principal is the landlord; while the landlord is responsible for installing and maintaining energy-using amenities, the agent or tenant is responsible for the payment of recurrent energy bills. Since the landlord does not reap the immediate benefits of investment in 
alternative energy-saving equipment, the financial incentive motivating such investment is weaker than for homeowners where ownership and use are not separated. On the other hand, tenants do not have the right to adapt their homes without landlord acquiescence, and any gains in asset value that accrue from energy-efficient investments are captured by the landlord.

The International Energy Agency (IEA), in an effort to quantify the magnitude of the split incentives problem, conducted eight case studies spanning five countries in both residential and commercial sectors and found significant evidence for its existence and prevalence The IEA estimated that in absolute terms, the global energy use attributed to the principal-agent problem was equivalent to around 85\% of the total energy use of Spain in 2005 (International Energy Agency, 2007, p191). In Australia, the Garnaut Climate Change Review (Garnaut, 2008) highlighted the importance of the principal-agent problem and expressed concern that renters have limited incentives to pay for the capital costs of installing energy-efficient equipment in their homes.

Governments in various countries have introduced policies that aim to improve energy efficiency in the private rental housing stock. For example, in the United Kingdom, the Landlords Energy Saving Allowance is a tax allowance that allows landlords to claim the cost of purchasing and installing energy-saving products in their rental properties. The UK has also promoted Green Landlords Awards to raise awareness of energy efficiency among tenants, encourage landlords to take up government incentives and reward landlords who have made energy efficient improvements to their rental properties. In New Zealand, landlords whose tenants hold community services cards are eligible for a rebate amounting to $60 \%$ of insulation costs incurred under the Warm up New Zealand program (Gabriel et al, 2010).

In Australia, the Federal government's Energy Efficient Homes Package allows landlords and tenants (as well as homeowners) of inadequately insulated homes to access rebates for the installation of ceiling insulation. In 2008, the Victorian State government's Sustainability Victoria initiative made rebates for insulation and gas hot water systems available to landlords where tenants were directly responsible for energy bills. But Gabriel et al's (2010) international review of initiatives concluded that Australian governments offered landlords relatively limited incentives to promote energy efficient investments. From a policy perspective, this is especially worrying given that Australia's per capita emissions are the highest among OECD countries. The annual per capita carbon emissions in Australia in 2006 were approximately 28 tonnes per person, nearly twice the OECD average and more than quadruple the global average (Garnaut, 2008).

In this paper we report the findings from an empirical inquiry that aims to measure the significance of split incentive issues for Australian private rental tenants' energy bills. More specifically, does market failure due to principal-agent problems contribute to higher energy bills for private renters, and leave them more vulnerable to the adverse consequences of increased energy prices than other housing consumers? Section 2 gives an overview of the relevant literature; section 3 explains methods, section 4 presents findings and section 5 concludes.

\section{Previous Studies}

Several empirical investigations have been conducted using household level data to identify the drivers of residential energy consumption. Important motives for these studies have been the role of property type, and hence urban form; the influence of personal characteristics, such as income, on the demand for energy; the importance of energy prices on choice of energy systems and consumption. Some studies have included housing tenure as a variable and therefore have a particular significance in the present context. Typically the data source is surveys specifically conducted for the purposes of analysing energy consumption; two exceptions are Rehdanz (2007) and Meier and Rehdanz, 2010), which are most similar in approach to our own, and are discussed further below.

Most studies include 3 key categories of variables in their models;

- Personal characteristics such as income and household size; 
- Property characteristics such as age, size, type and location, from which inferences about the effect of urban form are commonly deduced; and

- Climate variables that can be expected to influence energy consumption for heating and cooling purposes.

Some studies have also been careful to include energy price variables, though this is less common in those papers exploring the role of urban form (Holden and Norland, 2005; Kahn, 2000). Relative energy prices will be influential determinants of the type of space and water heating (and cooling) systems, and conditional on this choice, the level of energy prices should shape the amount of energy consumption. It often turns out that price elasticity estimates are low, as is expected when the focus is on short-run consumption. ii The vector of property characteristics commonly includes a variable distinguishing between dwellings that are owner occupied or rented. This variable is used to detect whether renters consume more energy than owner occupiers, all else equal. Dubin and McFadden (1984) find the energy consumption of homeowners to be insignificantly different from nonhomeowners using data from the United States. Bernard et al (1996) use an econometric approach similar to Dubin and McFadden. When applied to data sourced from a Canadian electricity provider they find consumption by owner occupiers to be significantly lower than renters. Vaage (2000) also tests for the impact of homeownership on energy consumption in Norway using regression analysis, and finds that energy demand is $20 \%$ lower among home owners.

Rehdanz (2007) samples 12000 German households from a multi-purpose national survey. Their household energy expenditures are modelled; on controlling for prices, personal and property characteristics the study detects lower energy expenditures if properties are owner occupied. Meier and Rehdanz (2010) adopts a similar approach, using 64000 observations from the 1991-2005 British Household Panel Survey. In terms of methodology and type of data, Rehdanz (2007) and Meier and Rehdanz (2010) are similar to that employed here. A key difference is that Rehdanz (2007) does not control for climate (though there are 'controls' for region) as Germany is mostly temperate and not nearly as diverse in temperature range as other countries in which similar studies have been conducted. However, Meier and Rehdanz (2010) do control for climate using data on heating degree days, a climate measure which we also utilise in our analysis.

Our paper makes at least one novel contribution. The Australian institutional and policy context is very different from European counterparts. It has a housing system that has never featured rent controls in the post World War II era, and where there is no substantive security of tenure legislation. This unregulated context is also characterised by the use of tax preferences that give private rental housing an important role as a tax shelter. We return to these important institutional differences in concluding remarks.

\section{Method}

\subsection{Data and sample design}

We conduct our analysis using the 2006 Household, Income and Labour Dynamics in Australia (HILDA) Survey. There are several characteristics of this dataset which make it helpful for measuring the relative influence of the determinants of energy consumption. The HILDA Survey is a nationally representative dataset that contains a wide range of variables representing the demographic, socioeconomic and housing characteristics of Australian households. In addition, the Survey contains information on the annual energy expenditure of households. Specifically, households are asked about their annual expenditure on electricity, gas and other heating fuel.

Our sample comprises households in private dwellings, that is, home owners, private renters, public renters and rent-free households that report their annual energy expenditure. It is therefore a potentially rich source of data for analyses of energy consumption patterns by housing tenure. We exclude certain groups of households from our analysis. First, households in non-private dwellings such as nursing homes, because it is unclear whether their energy expenditures are captured in 
payments for board and residence. Residents of mobile dwellings such as caravans and houseboats are also excluded as there will again be uncertainty over recorded energy expenditures ${ }^{\text {iii }}$. Second, there are a number of households who report annual energy expenditure of less than $\mathrm{A} \$ 100^{\mathrm{iv}}$; it is likely that these households have recently moved into their dwelling, or they are renters and residents of nonprivate dwellings whose energy expenditures are partly captured in their rent payments ${ }^{v}$.

Households that own property apart from their primary home may have reported energy expenditures on both their primary home and other properties. ${ }^{\text {vi }}$ The 2006 HILDA Survey is particularly useful in separating out households that own other properties as information on ownership of other properties can be derived from the Survey's special wealth module. We test for whether ownership of properties other than one's primary residence is correlated with higher energy expenditure in our model specifications but find no evidence of significant correlation between the two ${ }^{\text {vii }}$.

Retrofitting existing buildings with energy efficient amenities typically involves capital investment that requires access to credit in order to finance. The 2006 HILDA survey contains a special wealth module that allows measurement of a household's net worth and self reported difficulties in raising finance (borrowing or liquidity constraints). We expect liquidity constrained households with low net worth to reside in dwellings with less energy-efficient amenities.

The final sample comprises 4,986 households, of which 3,455 are home owners and 1,531 are renters. The exclusion rules result in the omission of 587 home owner households and 288 renter households. Both units of analysis and measurement are on a household basis. When measuring personal characteristics such as age and ethnicity, we have chosen those of the eldest person in the household. But the educational qualification variable used in the regression is that of the most highly qualified member in the household.

\subsection{Variable Measurement and Modelling Approach}

We invoke a modelling approach that relates energy expenditure to property and personal characteristics.

The critical explanatory variables are those identifying housing tenure and landlord type. The size and the statistical significance of these variables will be used to judge whether and to what extent the tenants of private rental housing have higher energy bills as a result of the blunt incentives associated with the principal-agent problem. Housing tenure is represented by a series of binary variables that identify owners, private renters, public renters and rent-free households. The reference group or omitted category is private renters ${ }^{\text {viii }}$. The use of such binary variables in regression models of household energy consumption is a standard approach in statistical analyses of split-incentive issues (see for example, Rehdanz, 2007 and Meier and Rehdanz, 2010); the sign, size and statistical significance of the owner variable coefficient is the critical test statistic.

Actual energy consumption is not reported in the HILDA Survey; we utilise a variable that represents annual household energy expenditure. There are three concerns with this variable. First, though the data set is longitudinal energy expenditure is not reported in each wave and so cross section models must be estimated. ${ }^{\text {ix }}$ Second, and equally if not more important, expenditure is not as precise as quantity measures of energy consumption. Energy prices do vary across state boundaries and so the use of state identifiers (see below) in a vector of controls will go some way to address this measurement issue ${ }^{\mathrm{x}}$. We also address the issue by reporting model estimates from various subsets of the data where variability of unit energy prices will be relatively limited. Previous studies have found demand to be price inelastic with short-run price elasticity estimates of around -0.20 (see Branch, 1993; Dubin and McFadden, 1984 and Nesbakken, 2001). Thirdly, HILDA elicits actual expenditures that will be net of energy rebates ${ }^{\mathrm{xi}}$ where the household is eligible, and will not include energy consumption in communal areas that can be included in strata fees or rents. Consider the first of these problems. Households are billed for their energy consumption by retailers who deduct rebates from the amounts due. When asked to provide annual energy expenditures, eligible consumers will respond 
with estimates of the amounts due in energy bills and these will understate consumption. We address this measurement error by repeating our empirical exercises using a restricted sample of households that has been identified as ineligible for rebates using a housing market microsimulation model that contains the parameters of the Australian-tax benefit system ${ }^{\text {xii }}$ (see Wood and Ong, 2008). Energy consumption in communal areas will affect energy measures for renters and owners living in apartments; we address this issue by controls for property type in regression models.

The other controls included in model specifications consist of variables representing location, climate, dwelling characteristics and the household's personal characteristics. There are three broad groups of location variables. One comprises a string of binary variables representing the state or territory of residence. Energy prices vary by location because diverse energy sources are relied on in different parts of the nation, and these energy sources will have different costs of production and hence prices. State and territory location serves as a crude proxy for energy price variations. To further account for climate differences a second sequence of binary variables are added representing location in major cities, inner regional areas, outer regional areas and remote or very remote areas. Each remote area represents an aggregation of non-contiguous geographical areas which share common characteristics of remoteness based on the Accessibility/Remoteness Index of Australia (ARIA) ${ }^{\text {xiii }}$. The third location variable represents the socio-economic profile of the neighbourhood of residence, and is employed to detect possible neighbourhood impacts such as peer group and bandwagon effects. Here, deciles of the 2001 Socio-economic Indexes for Areas (SEIFA) of advantage/disadvantage are used. The ten separate deciles reflect a continuum of advantage (high deciles) to disadvantage (low deciles). The index is based on variables such as the number of families with high incomes, number of people with a tertiary education and so on (Australian Bureau of Statistics 2003).

The state location variables are crude proxies for energy price variations because they will also pick up climate differences. Previous studies have used precise measures to represent climate differences; annual heating degree-days (HDDs) and annual cooling degree-days (CDDs). HDDs and CDDs are quantitative indices indicating demand for energy to heat or cool houses. They are based on how far the daily average temperature varies from a human comfort level. The Australian Bureau of Meteorology (BoM) (2010) calculates HDDs and CDDs using temperature thresholds that reflect human comfort levels ${ }^{\text {xiv }}$. The temperature thresholds are $18^{\circ} \mathrm{C}$ for HDDs and $24^{\circ} \mathrm{C}$ for CDDs; if the temperature falls below $18^{\circ} \mathrm{C}$ it is expected to generate a demand for energy to heat houses; if the temperature were to rise above $24^{\circ} \mathrm{C}$ we anticipate a demand for energy to cool houses.

Some studies have adopted different thresholds. For example, Ewing and Rong (2008) adopted a threshold of $65^{\circ} \mathrm{F}$ (or approximately $18^{\circ} \mathrm{C}$ ) to calculate both HDDs and CDDs; in a study on electricity demand, Reiss and White (2005) adopted a threshold of $60^{\circ} \mathrm{F}$ (or $16^{\circ} \mathrm{C}$ ) to calculate HDDs and $70^{\circ} \mathrm{F}$ (or $21^{\circ} \mathrm{C}$ ) to calculate CDDs. The $18^{\circ} \mathrm{C}$ and $24^{\circ} \mathrm{C}$ thresholds we use are similar to those Reiss and White (2005) employed. We also adopt this set of thresholds as Australia has a relatively warm climate compared to other countries where studies on energy consumption have been conducted. For example, using the $18^{\circ} \mathrm{C}$ threshold, Bernard et al (1996) estimated that the HDD for Quebec (based on the study's sample mean) is 4,844 . This is significantly higher than for Australian capital cities, with the HDD ranging from only 85 in Brisbane to 331 in Hobart when the $18^{\circ} \mathrm{C}$ threshold is used.

For each capital city, the maximum and minimum temperature reached on each day in 2006 was sourced from the Bureau of Meteorology. The average temperature for each day in 2006 was set equal to the midpoint lying between the maximum and minimum temperature achieved each day. If the average temperature was below $18^{\circ} \mathrm{C}$, the heating degrees (HDs) for that day are set equal to $18^{\circ} \mathrm{C}$ minus the average temperature. If the average temperature was above $24^{\circ} \mathrm{C}$, the cooling degrees $(\mathrm{CDs})$ for that day are set equal to the average temperature minus $24^{\circ} \mathrm{C}$. The HDDs (CDDs) for each capital city was then derived by summing up the HDs (CDs) over the entire year. It is not possible to calculate the HDDs and CDDs of regional areas. While the Bureau of Meteorology is able to provide daily temperatures for each regional centre, the HILDA Survey location variables are not 
disaggregated enough to allow one to identify each regional centre. Hence, the two climate variables (HDDs and CDDs) are only included in separate models of capital city residents' energy expenditures.

The third vector of variables includes dwelling characteristics. Here, we expect that dwelling size will have a positive association with energy expenditure. In the absence of actual dwelling floor size we rely on the number of bedrooms as a proxy. Different dwelling types are also expected to have differential impacts on energy expenditure; for example, residents of separate houses are likely to spend more on energy expenditure than residents of flats, holding all other factors constant. A series of binary variables representing residence in separate houses, semi-detached houses and flats, units or apartments are included in the model specification ${ }^{\mathrm{xv}}$.

The final vector of variables includes measures of household personal characteristics. Household size is an obvious determinant since the more people living in a dwelling, the higher the annual energy usage. The number of adults and children are included in models as separate variables. It is also potentially important to identify whether someone is normally at home during the day, as this will increase energy use as compared to a household whose members are away from the dwelling during the day. A household variable set equal to the number of adults unemployed or not in the labour force (excluding full-time students) is deployed to capture this effect. We hypothesise that ethnicity might be important (see Ewing and Rong, 2008); persons from warmer climates could demand more energy for heating because they are less tolerant of cooler conditions, whereas those from cooler climates might demand more energy for cooling. The ethnicity variable is coded by grouping respondents' countries of birth under one of the major regions of the Standard Australian Classification of Countries (SACC) (Australian Bureau of Statistics 1998) - Australia, Oceania and Antarctica, Northwest Europe, Southern and Eastern Europe, North Africa and the Middle East, South-east Asia, North-east Asia, Southern and Central Asia Americas, Sub-Saharan Africa. As household members may originate from different regions, the ethnicity of the household's oldest responding member is used. Age could be relevant to energy consumption because older persons socialise less (and are ceteris paribus more 'home loving' than their younger counterparts), and with ageing we become more averse to extreme temperatures.

The vector of personal characteristics includes various financial variables. Capacity to pay for energy use is captured by gross household income, a variable that is almost always present in energy consumption models. We do not use an equivalised income measure as the effect of household size and composition on energy expenditure has been captured in the variables representing the number of adults and children in the household. Current income can temporarily deviate from 'normal' income as a consequence of unanticipated events, and these transitory components to income may have little impact on energy use. This argument suggests that it is the unobservable normal or permanent income of the household that is relevant. We proxy this unobservable variable by the qualification of the household member with the highest educational level; net worth, that is assets less debt from all sources other than owner-occupied housing, is collateral that can secure borrowing, or be drawn on to finance investment in home retrofitting designed to lower energy consumption. The potential impact of liquidity constraints is explored by exploiting a variable in the HILDA Survey that records a respondent's difficulty in raising A $\$ 2,000$ in an emergency. Each adult household member is asked whether s/he could easily raise $\mathrm{A} \$ 2,000$, could raise $\mathrm{A} \$ 2,000$ though it would involve some sacrifices, would have to do something drastic to raise $\mathrm{A} \$ 2,000$, or couldn't raise $\mathrm{A} \$ 2,000$. Members of the same household may answer differently to this question; we have used the response of that member responsible for paying household bills. Finally, expenditure on electrical appliances could impact energy consumption; but there are two possible effects ${ }^{\mathrm{xvi}}$. Those with high expenditures could be replacing energy inefficient appliances and reducing energy consumption. On the other hand, high expenditures could be adding to the number of appliances and hence boosting energy consumption. The variable is added to the regression and inferences from the data allowed to determine which of these effects dominates.

The regression model is estimated by ordinary least squares (OLS). A Chi ${ }^{2}$ test of the null that a log transformation is required can be rejected. But one benefit of using the logarithmic functional form 
for the dependent variable is that heteroscedasticity can be reduced (Wooldridge, 2009, p191), and in any case a likelihood ratio test also rejects the null that no transformation to a linear specification is required $^{\text {xvii }}$. We report estimates using the log-linear functional form, but also estimate (and report) a linear specification that allows for interaction effects and the possibility that split incentives are only present among particular sub-groups of home owners. Table 1 lists the variables included in the regression, a brief definition and indicates whether they are binary or continuous variables.

Four log linear models are estimated corresponding to sample designs that differ in terms of their geographical coverage. The first includes all households that meet the criteria listed under the sample design section but excluding HDD and CDD measures that cannot be computed for regional centres. Instead, state and remoteness area variables are used to account to potential climate and price differences across locations. A second model includes HDD and CDD measures but is estimated on a smaller sample of households from state capital cities only (residents of Sydney, Melbourne, Brisbane, Adelaide, Perth and Hobart) ${ }^{\text {xiii }}$. These climate measures replace the state and remoteness area variables in the model.

The climate and location variables are crude proxy variables. In models three and four specifications are estimated using samples drawn from the two largest cities - Melbourne and Sydney. Variations in energy use associated with differences in climate can be safely ignored in these regressions. Furthermore, inter-state variations in energy prices are irrelevant and so the omission of a price variable is less important. By progressively narrowing the geographic coverage, we can judge whether findings regarding the size and strength of split incentive effects are robust as tighter constraints are placed on variations in climate and energy prices.

\section{Descriptive Statistics}

Contrary to expectations it turns out that the typical home owner spends AA $\$ 1330$ or $36 \%$ more on energy than the $A \$ 980$ spent by a typical renter in our sample ${ }^{\mathrm{xix}}$. But these averages reflect differences in property type and size that could obscure tenure related differences in energy consumption. Table 2 presents average energy expenditure comparisons by property type, size and tenure. We can see from these figures how important it is to control for property attributes. Average annual (2006) expenditures by occupants of detached housing is $\mathrm{A} \$ 1,304, \mathrm{~A} \$ 346(27 \%)$ higher than the average outlays incurred by residents in semi-detached/terraced, and an even larger A $\$ 423$ (32\%) higher than the average outlays incurred by residents of flats. Only $22 \%$ of detached housing is occupied by renters, yet they occupy $71 \%$ of flats. So this feature of the housing stock will boost home owner energy consumption; but even when we control for property type and compare expenditures associated with renter-occupied and owner-occupied detached housing, the latter have significantly higher energy expenditures - $\mathrm{A} \$ 1,357$ or $21 \%$ higher than the $\mathrm{A} \$ 1117$ annual expenditures incurred by renters occupying detached housing. We obtain the same higher expenditures by owners when comparing outlays in the two other types of housing - in fact the spending differentials are even wider with owners outspending renters by $54 \%$ in semidetached/terraced, and $30 \%$ in flats.

Size also matters. Occupants of detached housing with 4 or more bedrooms spend $A \$ 1,490$ per annum. This is 53\% more than the outlays (A\$976) typical among occupants of detached housing with 2 or less bedrooms. The size differentials are even wider at over $100 \%$ among semidetached/terraced. Similarly, energy expenditure is on average $61 \%$ higher among flat occupants with 4 or more bedrooms than those living in flats with 2 or less bedrooms ${ }^{\mathrm{xx}}$.. Home owners (renters) occupy dwellings that have an average 3.3 (2.6) bedrooms. This size differential will also raise energy consumption by owner occupiers. But on comparing owners and renters occupying housing of the same type and size, the weight of evidence suggests that owner energy consumption is higher. In every size and type category owner-occupants typically spend more than their renter-occupant counterparts, though the differential does narrow for some size and property types.

There are personal, climate and location characteristics that could distinguish owners and renters and that correlate with energy consumption. Owner occupier household incomes are typically higher; 
couples with dependents are more likely to be home owners and so on. Table 3 compares a range of relevant personal characteristics and location variables across Australian home owners and renters, with private and public renters listed separately. The key points are:

- The distribution of owner and renter occupied residences by state (and region) are similar

- As already pointed out home owners are much more likely to occupy energy 'guzzling' detached housing and larger housing is also more common among home owners, as is to be expected given their larger household size.

- The financial and demographic profile of owner occupiers and renter occupiers is very different. The former have higher incomes, even after adjustment for household size, and their net worth is healthier even on a housing exclusive measure. Unsurprisingly, binding liquidity constraints are less common among owners.

- Private renters have a number of important distinguishing characteristics. They are younger, which is relevant because studies have shown that energy consumption in the home is positively related to age. Their financial characteristics tend to lie at some point between those of home owners and public renters. Finally, tenant outlays on electrical appliances are around $28 \%$ less than those of home owners.

A comparison across capital cities indicates that Melbourne and Hobart have cooler climates while Brisbane clearly has the warmest climate.

This brief description of profiles highlights the importance of taking confounding influences into account. Split incentive effects could be masked by the higher incomes of owner occupiers, particularly if energy consumption is income elastic. Their larger homes will be more expensive to heat and cool, and it would seem that the type of housing most commonly occupied by owners is a more intensive user of energy, though whether this is due to the design and vintage of this housing, the heating and cooling systems generally used in detached housing, or other factors, is a moot point. The modelling exercises reported below control for the more important confounding factors.

\section{Findings}

Tables 4 and 5 report OLS regressions coefficient estimates, their robust standard errors and finally significance for the four log linear models described in section 3 (see page 4). Table 4 presents findings for all households Australia wide ${ }^{\mathrm{xxi}}$ and for households resident in state capital cities. Table 5 presents estimates for Sydney and Melbourne. Sample numbers are healthy (always exceeding 750 households).

Consider first the Australia-wide estimates, and the property variables in particular. With the exception of the critical split incentive test variable property characteristics have expected impacts on energy expenditure. In the all households estimates detached housing is found to be energy intensive (bills are 21\% higher than in one-storey semi-detached, row and terraced housing); large housing units are more expensive to heat and cool (each extra bedroom adds $16 \%$ to energy bills). But even after controlling for these and other factors expected to shape energy consumption, the bills of homeowners are estimated to be $15 \%$ higher than those of tenants in private rental housing. ${ }^{\text {xxii }}$ On estimating the same model but on households with energy consumption from one source (electricity), homeowner outlays are again estimated to be $15 \%$ higher. Thus the higher energy bills of homeowners is not due to differences in the source of power and related energy technologies.

The other variables reveal some potentially important patterns. Residents in the Southern States have higher energy bills, with those living in Victoria spending 18\% more than their New South Wales counterparts. Household size is a very important influence; each additional child under 15 (adult 15 years and over) adds $17 \%$ (25\%) to household spending on energy, a finding of relevance to the targeting of welfare programmes designed to alleviate energy poverty. We estimate a positive income elasticity, but it is low at 0.08 . According to Rehdanz (2007) the majority of studies estimate income elasticities between 0.08 and $0.17^{\text {xxiii }}$. Outlays on electrical appliances are also found to have a 
positive elasticity of 0.03 , suggesting that the effect these expenditures have on energy consumption is through an increased number of appliances rather than replacement of energy inefficient appliances. While the above variables are found to be significant, others are unimportant. Liquidity constraints, age and net worth are insignificant in one or more model specifications.

We find that the size and significance of the key variables, especially housing tenure, remain similar when the estimation sample is restricted to households ineligible for energy rebates. The restricted sample yields a similar owner energy bill premium of $16 \%$. Rebates do not seem to be masking split incentive effects ${ }^{\text {xiv }}$. In fact owner occupiers and renters are equally likely to be eligible for energy rebates $(30 \%$ (29\%) of owner occupants (private renters) are eligible for rebates), so the uniform estimates are unsurprising.

In table 4 we also report the results from a sample limited to residents of capital cities where we have an opportunity to more rigorously investigate the role of climate and its possible affect on other key variable estimates. The HDD and CDD variables are included at the expense of state dummy variables that are perfectly correlated with the HDD and CDD variables, making it impossible to disentangle the separate effects of climate and location. It turns out that the number of heating degree days is both statistically significant and quantitatively important, but the home owner coefficient remains positive and significant at the $1 \%$ level. A $10 \%$ increase in the number of heating degree days raises energy outlays by $3.9 \%$. It is then unsurprising to note that the all households model specification reported in table 4 finds that residents in the Southern states typically have higher energy bills (relative to a warmer New South Wales). On the other hand the number of cooling degree days has a much smaller impact. It is conceivable that in a predominantly warm country like Australia, temperatures that rise beyond human comfort levels prompt residents to spend more time outdoors, which curbs the need for expenditure on cooling and reduces outlays on other energy uses.

Table 5 presents finding when estimating regressions for residents of Sydney and Melbourne separately. This eliminates the effect of climate differences (and any unobservable variables that vary between state capitals). It also allows us to address a multicollinearity problem. Based on a capital cities sample, the correlation coefficient between the log of HDD and $\log$ of CDD is -0.806 (significant at the $1 \%$ level). Results remain consistent with the previous two models. Most importantly we have further confirmation that split incentive problems are absent. Home ownership continues to be associated with higher energy expenditure of $15 \%$ and $20 \%$ in Sydney and Melbourne respectively.

A consistent finding across different sample designs is that the average homeowner's energy expenditures are higher than those of comparable households in private rental housing, and so split incentive effects are not evident. A recent study by Meier and Rehdanz (2010) also fails to detect evidence of a split-incentive problem in Great Britain. It finds homeowner heating expenditures to be $2.8 \%$ higher than those of renters; this finding is statistically significant at the $1 \%$ level and holds after controlling for other factors such as property and household characteristics (see Meier and Rehdanz, 2010, table 2 column 2).

It is conceivable that particular subgroups of homeowners consume less energy than their tenant counterparts, and the binary owner status variable fails to detect these subgroup differences. Consider, for example, different income groups. Though all homeowners could be more motivated to invest in energy saving amenities, low income owners may not be able to afford the necessary capital outlays. Hence split incentive effects are only evident when higher income home owners are compared to private rental tenants with similar incomes. These ideas are investigated in a linear specification that adds an interaction between income and homeowner status (see table 6).

While estimates of a linear model without interactions suggests that the average owner spends $\$ 172$ per annum more on energy, the addition of an interaction between the owner binary variable and income offers apparent evidence of a split incentive effect among higher income home owners since the interaction variable has a negative coefficient (see table 6, columns 4), but this coefficient is insignificant. Table 6 also reports the estimates from a linear specification that tests for interaction 
effects with age ${ }^{\mathrm{xxv}}$. While the owner binary variable remains positive its interaction with age is negative and both coefficients are statistically significant. Nevertheless these estimates imply that homeowners at the sample mean age of 50 years spend $\$ 150$ more on energy than comparable tenants in private rental housing. Furthermore the sub-group of homeowners that spends less on energy than renters are confined to those aged 87 years or older ${ }^{\text {xxvi. }}$. This age group represents only $1.1 \%$ of the Australian population (Australian Bureau of Statistics, 2007) ${ }^{\mathrm{xxvii}}$, and so any effects are overwhelmed by the higher energy expenditures of owners belonging to younger age groups.

\section{Conclusion}

It would seem that the split incentive phenomenon is indeed unimportant. Since our models control for observable variables such as income, household size and so on that could be confounding influences what explanations might we offer for the higher energy outlays of home owners? One potentially important factor is the powerful tax incentives that motivate Australian landlords to hold residential investments with high building to lot ratios (Wood, Ong and Stewart, 2010). Land taxes on unimproved capital values that exempt owner occupiers but apply to property held by landlords, encourage the acquisition of housing with small lot sizes. On the other hand depreciation allowances on amenities (that will include energy saving appliances), building write off allowances for construction costs, the addition of retrofit capital outlays to the cost base used to compute taxable capital gains, the deduction of interest on borrowings to finance such retrofits and the lenient taxation of capital gains (relative to rental income) are all tax preferences that encourage landlord investment in the building rather than the land that rental properties 'sit on'.

We should also remark on the source of empirical studies that can be cited in support of the split incentive hypothesis. They have typically been conducted in Western Europe or North America where institutional arrangements are different. Rehdanz (2007, p18), explains that landlords in Germany have less of an incentive to improve on energy-efficiency because they have to bear the costs of improvements themselves, and adjustments in rental rates to recoup those costs are curbed by strict regulations. This observation suggests a market adjustment that is overlooked in the framing of a split incentives hypothesis. Tenants will pay lower bills when energy saving investments are made by their landlords. If there is competition between tenants for rental properties, and tenants are well informed, those landlords that have retrofitted will be able to capture a rent premium. Countries that have no rent regulation, such as Australia, could well find that the combination of tax preferences and rent premiums are sufficient to offset any split incentive effects ${ }^{\text {xxviii }}$. There is one additional related point. In some Western European countries (and some parts of North America), rent control is accompanied by security of tenure legislation that 'locks' landlords into their investments, and arguably deters maintenance of buildings. Critics argue that in such countries private rental housing will typically be older and dilapidated, and so lower energy consumption among owner occupiers is unsurprising. In Australia there is no such regulation and in fact there is considerable churning of properties in and out of the sector. In Wood and Ong (2010) we report that one quarter of landlords from a sample of over 600 'sold up' or 'moved in' within one year of them first being tracked in a longitudinal data set. The Australian housing stock could then be characterised by property careers that feature considerable movement back and forth between owner occupation and rental occupation, a feature much less likely in more regulated overseas housing markets ${ }^{\text {xxix }}$. There is much research to be completed here, and it will require a different approach that allows scrutiny of institutional differences across jurisdictions. But these are potentially important ideas in the present context as such churning would weaken the effect of split incentives, and indeed other barriers that might deter investment in energy efficient building construction designs and amenities.

However before dismissing the split incentives idea we should pay careful attention to a number of important caveats. There are at least three. The first is the absence of a satisfactory measure of the per 
unit energy prices households must pay. Closely related to this is a second weakness - the unobserved choice of space and water heating (or cooling) systems. A preferred approach since Dubin and McFadden (1984) is the simultaneous modelling of heating (cooling) systems and the demand for energy in a two stage estimation procedure. Finally, from an 'engineering and design' perspective the absence of an age variable could be worrying. Buildings of different vintages will differ with respect to energy efficiency, and it is conceivable that owner occupiers are more likely to reside in buildings of an earlier vintage than those occupied by tenants. This could mask important differences in energy consumption, but if split incentives are important you would expect owner occupiers to retrofit their older housing, and Australia's housing stock is believed to be of a recent vintage (as compared to Western European and US housing stocks), so this explanation is not compelling.

The findings reported in this paper could also have a bearing on a wider agenda. They suggest that policies on land use and zoning are likely to have major impacts on energy consumption. If we accept the estimates reported above, urban forms featuring large detached housing will boost the energy consumption of cities of any given population size. This confirms the findings from more elaborate and rigorous modelling which show that energy use per household increases significantly as the density of housing falls from multifamily structures, to row housing, to fully detached housing (Larson et al, 2010). The way we plan our cities and the policy instruments used to shape housing supply and demand may ultimately turn out to be more important than the tenure related issues prompted by split incentives.

\footnotetext{
${ }^{\mathrm{i}}$ Other end-use sectors include the commercial, industrial and transportation sectors.

ii Changes in relative prices are unlikely to immediately prompt changes in space and water heating systems because of the capital costs.

iii About $62 \%$ of residents in nonprivate or mobile homes don't actually report their energy expenditure.

${ }^{\text {iv }}$ Over half are living in rented property or are living rent free, and most (66\%) live in detached housing.

${ }^{v}$ Group households (unrelated persons who reside together in the same dwelling) are retained as we are interested in overall household energy consumption, that is the total energy consumption of all persons living in the same dwelling regardless of whether they are related or not.

${ }^{v i}$ The household member in charge of paying household bills is simply asked to provide their best estimate of the annual amount spent on electricity, gas and other heating fuel bills such as firewood and heating oil, without specific reference to whether the expenditure amount should relate to their primary home. There are 1234 households that own properties in addition to their primary place of residence.

vii Estimates are available for the authors on request.

viii The findings are not sensitive to choice of reference group.

${ }^{\text {ix }}$ At the time this study was completed, cross section modelling was the only option, but subsequent waves of the HILDA Survey have since been released that contain the energy expenditure variable. Hence, longitudinal analysis is a potential future direction for research. Energy expenditure variables were first made available in the HILDA Survey in its fifth wave (2005), and have since been reported in every subsequent wave up to the most recent wave 10.

${ }^{x}$ Other studies sharing the same limitation and using a region control include Rehdanz (2007). A report by the Australian Competition and Consumer Commission (2007) found that electricity prices ranged from 9.56 cents/kWh in the state of New South Wales to 16.04 cents $/ \mathrm{kWh}$ in the Northern Territory in 2003-4.

${ }^{x i}$ Each state government has energy rebate programs that offer a fixed dollar rebate to eligible households in all states other than Victoria, where rebates are tied to the dollar value of energy bills. Most energy rebates are for the use of electricity, the fixed rebate varies from a low of $\$ 118$ for households without dependent children in Western Australia to a high of $\$ 365$ in Northern Territory.

In Victoria and the Australian Capital Territory, the value of the rebates varies with respect to whether the concession is received in summer or winter. For example, in the Australian Capital Territory, the summer rate of concession is 25.15 cents per day while the winter rate is 92.2 cents per day. The Commonwealth government also offers a Utilities Allowance for energy, rates, water and sewerage costs. This is an amount that does not vary with the size of bills or household type and that eligibility is restricted to some income support payment recipients. Typically households eligible for energy rebates are low-income concession card holders such as holders of government-issued health care cards, pensioner concession cards, and Department of Veterans'
} 
Affairs concession cards for war widows and incapacitated war veterans. Households that are eligible for these concession cards have to first qualify for receipt of a government benefit. For example, to be eligible for the government-issued health care cards, households have to first be in receipt of one of the following government benefits: Newstart Allowance, Youth Allowance, Partner Allowance, Special Benefit, Widow Allowance, Parenting Payment, or the maximum rate of a family payment called Family Tax Benefit Part A.

xii AHURI-3M, a microsimulation model of the Australian Housing Market that contains a tax-benefit module, has been employed to identify households eligible for state government energy rebates. We apply government energy rebate parameters from the 2009 (the latest information available from State and Commonwealth government websites at the time the measurement of energy rebates was conducted) to ascertain rebate eligibility for households within our sample.

xiii The ARIA measures remoteness of a point based on the physical road distance between that point and the nearest urban centre. For example, major cities comprise collection districts (the smallest spatial unit used by the Australian Bureau of Statistics when collecting Census data) with an ARIA index of 0 to 0.2, while inner regions comprise collection districts with an average ARIA index greater than 0.2 but less than or equal to 2.4 (for further details, refer to Australian Bureau of Statistics, 2001).

${ }^{\text {xiv }}$ BoM also calculate HDDs and CDDs using alternative temperature thresholds of $12{ }^{\circ} \mathrm{C}$ and $18^{0} \mathrm{C}$ respectively. ${ }^{\mathrm{xv}}$ The energy bills for communal areas in multi-family housing (apartment blocks) could be met through strata fees that are not reported by owners and tenants as part of their annual energy expenditure. A strata fee is an amount payable by residents for the maintenance of an area shared by two or more properties that are linked together. For example, apartment residents tend to share common areas such as lifts, corridors or gardens.

The reported expenditures of residents of flats, apartments and units may then under-estimate energy consumption in these dwellings.

${ }^{\mathrm{xvi}} \mathrm{We}$ are grateful to an anonymous referee for pointing this out,

xvii Where a continuous variable is negative or zero, the $\log$ of the variable is set equal to zero as it is not possible to take the log of negative or zero values. Under the Box-Cox transformation procedure, the energy expenditure variable $y$ is transformed to $\left(y^{\lambda}-1\right) / \lambda$. Likelihood ratio tests are employed to test if $y$ should appear in linear $(\lambda=1)$ or $\log (\lambda=0)$ form (Kennedy, 2008). The likelihood ratio test statistic for the null hypothesis that $\lambda=0$ is 120.69 and permits rejection of the null at the $1 \%$ level of significance. The likelihood ratio test statistic for the null hypothesis that $\lambda=1$ is 4098.1 and also permits rejection of the null at the $1 \%$ level of significance. A linear model using levels of the continuous variables (including the dependent) yields (in the all household model) an $\mathrm{R}^{2}=0.147$. On computing the antilog of the predicted values from a log-linear model a very similar $\mathrm{R}^{2}=0.145$ is obtained when regressing actual expenditure values and these predicted values.

xviii Residents of Hobart are not separately identified and so all Tasmanian residents are included in the sample.

${ }^{x i x}$ Unless stated otherwise all differences in energy expenditures reported in this section are statistically significant at $5 \%$.

${ }^{\mathrm{x}}$ However, this difference in energy expenditure is only statistically significant at the $10 \%$ level.

${ }^{x x i}$ Households with energy bills less than $\$ 100$ per annum have been omitted (see method section). The exclusion does not affect the key implications of our modelling. On re-estimating the regression model with these households added back into the sample the homeowner coefficient increases from 0.143 in the restricted sample to 0.177 in the expanded sample (and again significant at the $1 \%$ level). A Chi ${ }^{2}$ test cannot reject the null (at the $5 \%$ level) that these coefficients are equal.

xxii The percentage impact estimates for binary variables are calculated from $\left(e^{\beta}-1\right)$, where $\beta$ is the estimated coefficient (see Halvorsen and Palmquist, 1980).

xxiii Our estimate is at the low end of this range. Nesbakken (1999) found that energy consumption was more price sensitive among high-income than low-income households; the absence of a satisfactory price variable could depress the income elasticity estimate.

${ }^{x x i v}$ In the all households estimates the homeowner coefficient is 0.142 and is significant at the $1 \%$ level. When estimated on a restricted sample that omits those eligible for energy rebates, the homeowner coefficient is 0.160 and is again significant at the $1 \%$ level. $\mathrm{A} \mathrm{Chi}^{2}$ test is unable to reject the null hypothesis of homeowner coefficient equality (a test statistic of 0.15 is highly insignificant)

${ }^{\mathrm{xx}}$ Linear models with the addition of interaction variables involving property type, education and number of bedrooms have also been estimated, but results fail to detect the presence of split incentive effects among any of the owner subgroups identified by the interaction variables. Results are available from the corresponding author. ${ }^{x x v i}$ At the mean age of 50.3 years energy expenditure is given by $353-4.04 * 50.3=150$. The age at which the interaction effect offsets the impact of the binary owner variable is found by solving for age in the equality 353 $-4.04 *$ age $=0$.

xxvii According to the Australian 2006 Census, persons aged 87 years or over made up 1.1\% of the Australian population in 2006 (Australian Bureau of Statistics, 2007).

xxviii Such rent premiums could also be capitalised into house prices. 
xxix This mobility of properties can also have negative impacts on tenants' wellbeing, particularly ontological security, but this is outside the scope of this study.

\section{References}

Andrews, D., A. Caldera Sánchez and Å. Johansson (2011), "Housing Markets and Structural Policies in OECD Countries", OECD Economics Department Working Papers, No. 836, OECD Publishing.

Australian Bureau of Meteorology (2010), Average annual \& monthly heating and cooling degree days. http://www.bom.gov.au/jsp/ncc/climate_averages/degree-days/index.jsp (accessed 17 March 2010).

Australian Bureau of Statistics (1998), Standard Australian Classification of Countries (SACC), Cat. No. 1269.0, Australian Bureau of Statistics, Canberra.

Australian Bureau of Statistics (2001), Statistical Geography Volume 1 Australian Standard Geographical Classification (ASGC) 2001, Cat. No. 1216.0, Australian Bureau of Statistics, Canberra.

Australian Bureau of Statistics (2003), Census of Population and Housing: Socio-economic Indexes for Areas (SEIFA), Australia, Cat. No. 2033.0.30.001, Australian Bureau of Statistics, Canberra.

Australian Bureau of Statistics (2007), 'Age (Full Classification List) by Sex', 2006 Census of Population and Housing, Cat. No. 2068.0, Australian Bureau of Statistics, Canberra.

Australian Competition and Consumer Commission (2007), State of the Energy Market 2007, Available: http://www.accc.gov.au/content/index.phtml?itemId=916636

Bernard, J., Bolduc, D. \& Bélanger, D. (1996), Quebec Residential Electricity Demand: A Microeconometric Approach, The Canadian Journal of Economics, 29(1), 92-113.

Branch, E.R. (1993), Short run income elasticity of demand for residential electricity using consumer expenditure survey data, Energy Journal, 14(4), 111-121.

Dubin, J. A. and McFadden, D. L. (1984), An econometric analysis of residential electric appliance holdings and consumption. Econometrica, 52, pp. 345-362.

Ewing, R. and Rong, F. (2008). The impact of urban form on U.S. residential energy use, Housing Policy Debate, 19,1-30.

Gabriel, M., Watson, P., Ong, R., Wood, G. and Wulff, M. (2010), The Environment Sustainability of Australia's Private Rental Housing Stock, Positioning Paper No. 125, Australian Housing and Urban Research Institute, Melbourne.

Garnaut, R. (2008), The Garnaut Climate Review: Final Report, Cambridge University Press, Melbourne.

Halvorsen, R. and Palmquist, R. (1980), The interpretation of dummy variables in semilogaritmic equations, American Economic Review, 3, 474-75.

Holden, E. and Norland, I. T. (2005), Three challenges for the compact city as a sustainable urban form: household consumption of energy and transport in eight residential areas in the Greater Oslo region, Urban Studies, 42, pp. 2145-2166.

International Energy Agency (2007), Mind the Gap: Quantifying Principal-Agent Problems in Energy Efficiency. France

Kahn, M. E. (2000), The Environmental Impact of Suburbanization. Journal of Policy Analysis and Management 19(4), pp. 569-86. 
Kennedy, P. (2008), A Guide to Econometrics, $6^{\text {th }}$ Edition, Blackwell Publishing, Oxford.

Larson, W., Liu, F. \& Yezer, A. (2010), Energy Footprint of the City: Effects of Urban Land Use and Transportation Policies, November, Available at SSRN: http://ssrn.com/abstract=1696056

Meier, H. And Rehdanz, K. (2010), Determinants of residential space heating expenditures in Great Britain, Energy Economics, 32, pp. 949-959.

Nesbakken, R. (1999), Price sensitivity of residential energy consumption in Norway, Energy Economics, 21, 493-515.

Nesbakken, R. (2001), Energy Consumption for Space Heating: A Discrete-Continuous Approach. Scandinavian Journal of Economics, 103(1), pp. 165-184.

Rehdanz, K. (2007), Determinants of residential space heating expenditures in Germany. Energy Economics, 29(20), pp. 167-182.

Reiss, P.C. and White, M.W. (2005), Household electricity demand, revisited. The Review of Economic Studies 72(3): 853-883.

Vaage, K. (2000), Heating technology and energy use: a discrete/continuous choice approach to Norwegian household energy demand, Energy Economics, 22, pp. 649-666.

U.S. Energy Information Administration (2009), Emissions of Greenhouse Gases in the United States 2008, U.S. Energy Information Administration, Available: http://www.eia.doe.gov/oiaf/1605/ggrpt/pdf/0573(2008).pdf

Wood, G. and Ong, R. (2008), Redesigning AHURI's Australian Housing Market Microsimulation Model, Report, November, Australian Housing and Urban Research Institute, Melbourne.

Wood, G. and Ong, R. (2010), Factors Shaping the Decision to become a Landlord and Retain Rental Investments, Final Report No. 142, Australian Housing and Urban Research Institute, Melbourne.

Wood, G. Ong, R. \& Stewart, M. (2010), Housing taxes and the supply of private rental housing, in Stewart, M. (eds.) (2010) Housing and Tax Policy, Melbourne: Australian Tax Research Foundation, pp. 163-180.

Wooldridge, J.M. (2009), Introductory Econometrics, $4^{\text {th }}$ edition, Ohio: South-western Cengage Learning. 